\title{
O LEGADO DE KANT À FILOSOFIA DO DIREITO*
}

\author{
Soraya Nour \\ Doutora. Graduada em Direito - USP; \\ Mestre. Graduada em Filosofia, Sociologia e Ciência Política - Universidade de Frankfurt; \\ Pesquisadora - Universidade Paris X. \\ sorayanour@yahoo.com
}

\section{resumo}

Este artigo mostra como Kant define de modo intersubjetivo princípios de justiça nos quadros do direito natural não-positivo. A primeira parte mostra como ele atribui ao direito estatuto de ciência; a segunda, a maneira pela qual, a partir dos conceitos de liberdade como autonomia e limitação recíproca, constrói um paradigma de direito. De acordo com este modelo, pode-se, por fim, analisar como Kant estrutura sua Doutrina do direito em direito privado (subdivido em direito das coisas, pessoal e pessoal de modo real) e em direito público (subdivido em direito do Estado, das gentes e cosmopolita).

Unitermos: Direito natural. Intersubjetividade. Justiça. Kant. Liberdade.

*Texto desenvolvido a partir do trabalho publicado em 2004, financiado pela Alexander von Humboldt-Stiftung e pela Universidade de Paris X. 


\section{KANT'S LEGACY TO THE PHILOSOPHY OF LAW}

\section{abstract}

This article shows how Kant defines principles of justice in an intersubjective way in terms of natural law. Firstly, it is shown how Kant attributes to law the statute of science; secondly, how Kant, with the concepts of freedom as autonomy and reciprocal limitation, constructs an intersubjective juridical paradigm. Finally, it is possible to analyse how Kant, according to this model, structures his Doctrine of law in private and public law.

Uniterms: Freedom. Intersubjectivity. Justice. Kant. Natural law. 


\section{Critérios de justiça}

Tmmanuel Kant é habitualmente considerado o fundador do 1 positivismo jurídico (CATTANeO, 1981, p. 101-102), visão apresentada também pelo jurista francês Michel Villey, para quem o filósofo teria definido de modo rigoroso, como limites da ciência do direito, os estudos das leis positivas garantidas por sanções. De acordo com Kant, entende Villey (1976, p. 145), o jurista deve-se deter apenas no exame do direito positivo e nele encontrar todas as soluçóes para qualquer tipo de problema jurídico com o qual depare: "E é então que se abre a era (a partir de 1804 na França, mais tarde na Alemanha) do 'positivismo legalista'."

Esta interpretação de Kant, tal como apresentada por Villey, comete, no entanto, um equívoco: além de, em nenhum momento, prescrever ao jurista que se limite ao exame do direito positivo, ainda condena, na sua Doutrina do direito (Rechtslehre), justamente essa visão positivista do direito e do jurista. Na 'Introdução' a esta sua obra (Einleitung in die Rechtslehre), distingue claramente o direito natural (jus naturae) do direito positivo, determinando como objeto de sua investigação o direito natural.

A distinção entre o direito natural e o direito positivo é apresentada nos $\oint \oint \mathrm{A}$ e $\mathrm{B}$. Quanto à sua existência, o direito natural estabelece princípios a priori que independem da legislação positiva, na qual podem ou não ser consagrados, enquanto o direito positivo é o que "existe efetivamente", isto é, as leis de um certo lugar em uma certa época; quanto a sua fonte, o direito natural procede da razão, enquanto o direito positivo advém da vontade do legislador (KANT, 1797, p. 237); quanto à justiça, o direito natural busca responder à questão "o que é de direito", ou seja, o que é justo e o que é injusto (iustum et iniustum), enquanto o direito positivo responde à mesma questão afirmando o prescrito pela lei; por fim, quanto à fundamentação, é no direito natural que devem ser buscados os princípios de todo direito positivo (op. cit., p. 229-230). O direito natural, sendo o fundamento do direito positivo, tem, portanto, prioridade - é o 'cérebro' de qualquer doutrina empírica do direito. Kant define então sua Doutrina do direito como "o conjunto das leis para as quais uma legislação exterior é possível” (idem), ou seja, as leis do direito natural às quais deveria corresponder todo direito positivo (o que freqüentemente não é o caso). 
A determinação do direito natural como fundamento do direito positivo representa uma crítica tanto ao direito positivo dogmático, que não pergunta pela justiça, como a um direito natural dogmático, que dispensa o direito positivo; se, por um lado, o direito positivo deve buscar seu fundamento no direito natural, por outro, uma comunidade não pode ser governada apenas pelo direito natural, e sim pelo direito positivo que o direito natural deve fundar. A Doutrina do direito não tem, portanto, a pretensão de elaborar um sistema jurídico que subsista por si, mas apenas os critérios de justiça de qualquer legislação positiva. Além disso, como observa Höffe, a crítica ao direito positivo que não atende aos critérios de justiça é também uma crítica a teorias positivas do direito que, investigando sua auto-regulamentação e processos de poder, não indagam o que é justo ou injusto (HÖFFE, 1998, p. 206).

Kant diferencia três tipos de direito: direito natural (naturrecht), direito privado (natürliches recht) e direito público (öffentliches recht). Enquanto o direito natural (naturrecht) corresponde, como foi visto, a critérios a priori de justiça, o direito em condição natural (natürliches recht) corresponde ao conjunto de leis que podem ser legitimamente pensadas independentemente de instituições jurídico-políticas que o assegurem corresponde às leis da sociedade, mesmo sem o Estado, e que se considerava na época como o direito privado: "o conjunto de leis que não precisam de uma declaração exterior” (KANT, 1797, p. 242). Já o direito público (öffentliches recht) corresponde ao direito das instituições políticojurídicas: "o conjunto de leis que necessitam de uma declaração pública." (idem) Isso significa, portanto, que a divisão interna principal da Doutrina do direito de Kant não é entre um estado de natureza desprovido de direito e um estado jurídico, mas, sim, entre sociedade, na qual rege o direito privado, e Estado, regido pelo direito público, ou seja, as instituições político-jurídicas que asseguram o cumprimento do direito privado (idem). Tanto o direito privado quanto o público têm seus princípios de justiça determinados pelo direito natural. Assim, a Doutrina do direito, ao ter por objeto o direito natural, assume a tarefa de investigação dos princípios de legitimidade do direito privado e do direito público.

O equívoco da interpretação de Villey é acompanhado por um erro de tradução. A tradução francesa da Doutrina do direito por ele prefaciada, publicada pela Editora Vrin, ignora a distinção entre natürlichem recht e 
naturrecht; a tradução de Joëlle Masson e Olivier Masson para a Editora Pléiade, de 1986, corrige esse erro. A tradução feita por Alain Renault para a Flammarion, em 1994, mantém essa correção, justificada na Présentation:

confundir os dois falando a cada vez em direito natural' era dar crédito (já que Kant sustenta que o natürliches recht só adquire consistência pelo direito público) à lenda absurda, mas persistente, segundo a qual Kant, submetendo o direito natural ao direito público, prepara o positivismo jurídico - lá onde no texto não se diz nunca que o naturrecht encontra sua verdade nos sistemas de direito positivo existentes (que ao contrário, enquanto 'dever-ser', ele permite julgar (RENAULT, 1994, p. 39).

As competências jurídicas são então diferenciadas conforme tal distinção entre direito natural e direito positivo: a jurisprudência (iurisprudentia, rechtsklugheit) é definida como o conhecimento técnico do direito positivo e de sua aplicação; douto em direito (iurisconsultus) é o que conhece apenas as leis positivas; prático em direito é o que, além de conhecer as leis positivas, sabe como aplicá-las (iurisperitus); jurisciência é o conhecimento sistemático do direito natural, ou seja, dos critérios de justiça do direito (KANT, 1797, p. 229). Na Crítica da razão pura, o filósofo define ciência em sentido amplo como o conjunto de proposições gerais, permitindo considerar a doutrina positiva do direito como ciência. No entanto, ciência em sentido estrito é definida como o conjunto de princípios a partir dos quais se adquire conhecimento de um certo objeto, o que leva a definir apenas o direito natural como ciência (KANT, 1781, p. 329). A prioridade dos princípios do direito natural em relação à multiplicidade de leis positivas é assim justificada de dois modos distintos, tal como observa Höffe (1998): epistemologicamente, na Crítica da razão pura, por ser o conhecimento a partir de princípios; normativamente, no $\S$ A da Doutrina do direito, por ser o conhecimento dos princípios de justiça de toda legislação positiva. 


\section{Intersubjetividade}

Kant concebe a comunidade jurídica intersubjetivamente como união sistemática (por meio de leis comuns, e não arbitrária) de todas as pessoas como fim em si (uma pessoa não é meio para outro fim) e do fim particular que cada pessoa tem (o que cada um entende por felicidade). As leis comuns no direito, ou seja, as leis jurídicas, constituem, ao lado das leis éticas, uma subdivisão das leis morais. Assim, Kant confere às leis jurídicas estatuto moral ao mesmo tempo que as diferencia das leis éticas a partir de uma análise da dupla composição de toda legislação. Tanto a legislação jurídica quanto a ética são compostas de uma parte objetiva, a lei que prescreve a ação a ser realizada, e de uma parte subjetiva, a motivação da ação, o que me leva a cumprir o que a lei prescreve (KANT, 1797, p. 219). O dado objetivo da legislação, a lei, é a mesma para o direito e para a ética: o imperativo categórico, fundado na noção de liberdade como autonomia - a máxima que o sujeito segue, e que ele próprio concebeu, é de tal ordem que todos poderiam aceitá-la, valendo como lei universal (todos dariam a ela seu consentimento) sem que o sujeito abra uma exceção para si (que a lei só valha para si, mas não para os outros, ou que só valha para os outros, mas não para si). No direito, o princípio da autonomia significa a "faculdade de não obedecer a nenhuma lei externa senão àquelas às quais possa dar meu consentimento" (KANT, 1795, p. 350). Daí sua pretensão de universalidade e seu caráter moral. Entretanto, pelo dado subjetivo da legislação - o que me motiva a agir - direito e ética se diferenciam: na legislação ética, a própria idéia de dever é o que me move a agir; na legislação jurídica, ao contrário, é indiferente o motivo pelo qual ajo.

O direito deve possibilitar que cada um possa perseguir seus fins, sem que seja privado de tal possibilidade ou prive os outros de fazerem o mesmo, isto é, sem interferir nos objetivos dos outros. A relação recíproca entre os arbítrios de cada pessoa deve ser assegurada. O conceito de liberdade como autonomia, entretanto, que significa obedecer apenas à lei a que todos poderiam dar seu consentimento, não explicita a perseguição dos objetivos particulares. Kant introduz então, na Doutrina do direito, um outro conceito de liberdade (que mantém ao lado do conceito de liberdade como autonomia): o de liberdade como limitação recíproca do arbítrio (TERRA, 1995, p. 81-85). Assim, o direito é definido como "o conjunto das condições sob as quais o arbítrio de um pode ser conciliado com o arbítrio do outro segundo uma lei universal da liberdade" (KANT, 1797, p. 230). 
$\mathrm{O} \oint \mathrm{B}$ da Doutrina do direito investiga antropologicamente as condições humanas que justificam a necessidade do direito. Nele, o autor delineia uma antropologia do direito que se distingue de uma antropologia moral (condições antropológicas de execução da lei) (op. cit., p. 217), de uma antropologia fisiológica (o homem visto como ser da natureza) e de uma antropologia pragmática (o que homem pode e deve fazer de si próprio) (KANT, 1798, p. 119). Höffe (1998) observa que o resultado obtido é análogo ao dos Primeiros fundamentos metafísicos da natureza, obra na qual Kant afirma que a metafísica da natureza é insuficiente sem um objeto da experiência; a metafísica da física tem como objeto o conceito empírico de matéria, e a metafísica da psicologia, o conceito empírico de um ser pensante (KANT, 1786, p. 469-470). A aplicação dos princípios da metafísica da física necessita ainda de outros conceitos empíricos, como o de movimento (op. cit., p. 476). Por analogia, a aplicação dos princípios a priori da metafísica também se dá sobre um objeto da experiência, um fato empírico geral que é a coexistência de seres racionais finitos. A aplicação do direito é determinada pelo dado empírico da vida em comum das pessoas, sujeita a duas outras condições empíricas: a limitação do mundo exterior obriga as pessoas a conviver ("pois a Terra não é uma superfície infinita, mas sim fechada em si mesma”) (KANT, 1797, p. 311); o corpo extenso das pessoas (que não são portanto pura inteligência) necessita de uma parte física desse mundo comum. A antropologia do direito é assim constituída por tais condições empíricas da humanidade, que estabelecem entre os seres humanos uma relação que não é apenas teórica ou estética (contemplativa), e sim prática (op. cit., p. 216).

A essa antropologia de uma relação social inevitável corresponde uma concepção jurídica intersubjetiva, considerada como a primeira condição do direito; este "só concerne à relação exterior, e na verdade prática, de uma pessoa com outra, de modo que suas açóes, como fatos, possam (imediata ou mediatamente) influenciar-se entre si" (op. cit., p. 230). O caráter obrigatório do direito decorre então do fato de que a influência mútua que as pessoas exercem umas sobre as outras não advém de forças naturais, e sim de atos imputáveis de sujeitos responsáveis (op. cit., p. 223 227). A segunda condição é que se pensa apenas a relação entre os arbítrios, e não entre desejos ou necessidades, que caracterizariam uma relação antes beneficente do que jurídica (op. cit., p. 230). Sendo o arbítrio a faculdade de 
fazer ou não algo da forma que se queira (op. cit., p. 213 e 230), a relação jurídica ocupa-se portanto da liberdade da ação, e não da liberdade da vontade. A terceira condição do direito é que considere apenas a forma da relação recíproca dos arbítrios, e não a matéria (o fim). Assim, por exemplo, cada povo tem uma concepção distinta do que seja bem-estar e prosperidade - fins empíricos que Kant chama, em geral, de felicidade, e que não podem ser determinados pela razão (KANT, 1793, p. 290); esta pode legislar apenas sobre o que é necessário e universal, e seria tirânica se invadisse o domínio do particular. É tirânico um direito natural que tenha a pretensão de definir o que seja o bem-estar e a prosperidade, tal como fazia o direito natural da época do filósofo, principalmente com sua concepção de civilização. Kant condena a dominação exercida pelos europeus sobre outros povos com o pretexto de promover sua civilização, pois um povo não pode impor a outro o que entende por esse conceito (KANT, 1797, p. 353). Do mesmo modo, cada povo, com sua concepção peculiar de prosperidade, deve decidir por si, sem interferência de outro Estado, sobre a interdição de importação para promover a produção por parte de seus próprios cidadãos (KANT, 1793, p. 298). Kant considera ainda despotismo que um Estado imponha seu conceito de felicidade aos seus cidadãos, como se esses fossem crianças: "O Soberano quer fazer o povo feliz de acordo com seu conceito de felicidade, e torna-se déspota; o povo não quer que lhe tirem sua reivindicação humana e universal à própria felicidade, e torna-se rebelde" (KANT, 1797, p. 302).

A partir dessas condições de aplicação do direito, Kant formula seu conceito: "O direito é pois o conjunto das condições sob as quais o arbítrio de um pode unificar-se com o arbítrio do outro de acordo com uma lei universal da liberdade" ( $(B)$. O que possibilita verificar a legitimidade ou não do direito é a lei universal de liberdade, ou seja, o imperativo categórico (op. cit., p. 230), que garante com isso a coexistência da liberdade de ação (HÖFFe, 1998, p. 222). A esse conceito de direito corresponde o seguinte princípio universal, como critério de justiça: "é justa toda ação que permite (ou cujas máximas permitem) que a liberdade do arbítrio de cada um coexista com a liberdade de qualquer outro segundo uma lei universal, ou cuja máxima permite esta coexistência" (KANT, 1797, p. 230). Se o conceito de direito se refere a um direito objetivo, o princípio que lhe corresponde está relacionado, por sua vez, a um direito subjetivo, uma pretensão 
subjetiva (op. cit., p. 230), formulada nos seguintes termos: "quando assim minha ação, ou sobretudo meu estado, pode conviver com a liberdade de qualquer um de acordo com leis gerais, então aquele que me impede disto comete uma injustiça contra mim" (op. cit., p. 230). A esse conceito e a esse princípio de direito corresponde por fim a seguinte lei universal do direito enquanto prescrição da ação: "aja exteriormente de tal maneira que o livre uso de seu arbítrio possa coexistir com a liberdade de qualquer um segundo uma lei universal" (op. cit., p. 231).

Dois elementos fundamentais estão presentes no conceito, no princípio e na lei universal do direito: a relação mútua dos arbítrios, que pressupõe uma concepção de liberdade como limitação recíproca (os limites da liberdade de cada um são determinados pela liberdade do outro) e a lei universal, que pressupóe uma concepção de liberdade como autonomia, pela qual o direito faz parte da moral (Terra, 1995, p. 81). ${ }^{1}$ Com esses dois conceitos de liberdade, Kant estabelece uma vinculação entre princípios universais da razão prática e a natureza particular da vida das pessoas (KAUlBACH, 1982, p. 300): o ser humano é considerado ao mesmo tempo ser racional, que segue a lei moral (a qual todos poderiam dar seu consentimento), e ser que persegue seus interesses particulares (sua própria concepção de felicidade), sem impedir os outros de fazerem o mesmo (op. cit., p. 305).

Toda a concepção jurídica kantiana pressupõe, desde seu início, a intersubjetivdade. A Doutrina do direito não parte da noção de indivíduo, ou seja, da usual distinção entre o ser humano fora da sociedade, em um estado de natureza, e o ser humano em sociedade, vinculado aos demais pelo contrato social - modelo que considera os indivíduos como pontos isolados a serem unidos artificialmente (LEBRUN, 1986, p. 80); ao contrário, parte da noção de indivíduo como membro de uma comunidade - seja uma comunidade sem Estado (direito privado), ou com Estado (direito público)

\footnotetext{
1 Enquanto Lisser (1978) prioriza a noção de liberdade como autonomia, Solari prioriza a de liberdade como limitação recíproca: "moral e direito, conforme à tendência dualística que informa toda a obra kantiana, são estranhos um ao outro, ignoram-se, desenvolvem-se em campos fechados e opostos" (1974, p. 24). Forschner, assim como Solari, afirma que "o direito assegurado pelo Estado deve ser entendido como limite" (1977, p. 83); assim, a idéia moderna liberal do direito encontraria em Kant sua formulação clássica (op. cit., p. 107). Terra, ao contrário destas duas leituras, mostra como as duas noções de liberdade são igualmente fundamentais no conceito de direito de Kant (1995, p. 83-85).
} 
(GERHARDT, 1995, p. 53-54). Apesar de manter a linguagem da tradição, Kant funda filosoficamente a distinção entre sociedade e Estado, a fim de, como é hoje usual nas teorias políticas contemporâneas, também investigar a relação entre sociedade e Estado (RENAULT, 1994, p. 35); com isso, a Doutrina do direito vai além das teorias do direito natural moderno, ocupadas principalmente com a questão da legitimidade e da soberania.

Dado que Kant parte de uma concepção intersubjetiva, assim também seu direito privado não concebe a propriedade como individual; o direito das coisas (primeira parte do direito privado) funda-se antes na noção de uma propriedade comum de todas as pessoas sobre todas as coisas. $\mathrm{O}$ direito de propriedade não é, portanto, fundamentado em uma relação jurídica imediata entre o livre arbítrio de uma pessoa e uma coisa. Possuir algo significa não uma relação imediata entre certa pessoa e uma coisa, e sim uma relação imediata entre essa pessoa e todas as outras - que se encontram, portanto, em uma relação jurídica de propriedade comum sobre essa coisa e sobre a qual aquela certa pessoa tem apenas o direito de uso privado (KANT, 1797, p. 260-261).

Também o direito pessoal (segunda parte do direito privado) - o direito que surge quando uma pessoa incumbe outra de determinada ação, como por exemplo no contrato de compra e venda, em que um deve transferir a propriedade da mercadoria e outro pagar o preço - também tem fundamento intersubjetivo. Disso decorre que apenas o contrato pode originar tal direito. Kant se opõe às teorias tradicionais de sua época ao insistir que um direito pessoal não pode ser “jamais nem originário, nem arbitrário" (op. cit., p. 271); por nascimento ou imposição (como era então usual), não se pode ter obrigaçóes a cumprir. A terceira parte do direito privado, que o filósofo denomina "direito pessoal de modo real", condena as teorias tradicionais que viam a relação familiar como uma relação de propriedade que o senhor teria sobre seus dependentes - esposa, descendentes e servos -, para considerá-la como uma relação entre seres livres que constituem uma sociedade (op. cit., p. 276).

A fim de que o direito privado seja assegurado, é necessária a formação de instituições jurídico-políticas, o direito público - cuja tarefa é assegurar relações já existentes entre as pessoas e por elas livremente estabelecidas. Como analisa Höffe, 
[...] desaparece com isso o poder do Estado. A propriedade de coisas, o contrato, o casamento, a família e a sociedade familiar são instituições jurídicas pré-estatais [...] $\mathrm{O}$ Estado é uma instituição de segunda ordem, que serve às instituiçóes de primeira ordem, a saber: a propriedade de coisas, o contrato, assim como o casamento e a família. (HÖFFE, 1996, p. 225-226).

A intersubjetividade do direito expressa-se no direito publico em três níveis de ligação entre as pessoas: ligação entre as pessoas constituindo o direito do Estado; dos Estados entre si, constituindo o direito das gentes, e de todas as pessoas do mundo entre si, constituindo o direito cosmopolita. No direito do Estado, a noção de autonomia implica republicanismo, ou seja, exigência de que o povo dê a si próprio sua constituição - com o que Kant opõe à noção de súdito a noção de cidadão, modificando assim a relação entre governante e governado nas teorias tradicionais do Estado (KANT, 1797, p. 314). No plano internacional, essas repúblicas devem unirse, constituindo uma Liga de Estados regida pelo direito internacional (Terra, 1995, p. 72). Kant recusa a idéia de um Estado mundial, um "despotismo" que impediria a formação de uma ordem internacional marcada pelo pluralismo jurídico e político (KANT, 1795, p. 367). Por fim, as pessoas, como cidadãs do mundo, também devem ser unidas, conforme o direito cosmopolita - e que, ao contrário dos dois anteriores, tem um caráter restritivo: ele deve limitar-se à hospitalidade universal (op. cit., p. 357), ou seja, ao direito de visitar (op. cit., p. 358) todos os lugares da Terra sem ser tratado como inimigo (KANT, 1797, p. 352). Tal caráter restritivo visa condenar a colonização (HAMBURGUER, 1959, p. 316):

$\mathrm{Na}$ Índia oriental (Hindustão), sob pretexto de estabelecer sucursais comerciais, eles [os europeus] desembarcaram tropas estrangeiras, com as quais oprimiram os nativos, incitaram seus diversos Estados a extensas guerras, expandiram a fome, a rebelião, a perfídia e todos os males que afligem a humanidade. A China e o Japão, que tiveram sua experiência com estes hóspedes, recusam-lhes sabiamente, senão o acesso, ao menos a entrada em seu país (KANT, 1795, p. 358-359). 
A concepção jurídica de Kant foi, desde seu surgimento, profundamente ampliada, mas em nada perdeu sua atualidade. A luta pela conquista de direitos e por sua extensão às mais amplas dimensões sociais, econômicas e culturais da vida em sociedade, bem como a luta para que direitos conquistados se tornem efetivos, ocorre hoje tanto nos países a serem democratizados quanto naqueles cuja democracia se reduziu ao direito de voto e os demais direitos vêm sendo constantemente suprimidos; a reivindicação de que os conflitos entre os Estados sejam resolvidos pelo direito internacional, e de que os Estados se coordenem em organizações internacionais nas quais não haja imposição da vontade de uma parte sobre as outras, é feita hoje pelos que se opõem à estrutura oligárquica da Organização das Nações Unidas (ONU) e às tendências neoliberais das organizações internacionais; a crítica à colonização se revigora nos países centrais e periféricos pela condenação do que se chama hoje de neo-imperialismo ou império, em sua forma econômica, política, cultural e militar.

\section{Referências}

Cattaneo, Mario A. Dignità umana e pena nella filosofia di Kant. Milão: Giuffrè, 1981.

FORSCHNER, Maximilian. Rousseau. Freiburg am Breisgau/München: Karl Alber, 1977.

GeRHARDT, Volker. Immanuel Kant entwurf "zum ewigen frieden." Eine theorie der politik. Darmstadt: Wissenschaftliche Buchgesellschaft, 1995.

Hamburguer, Ernest. Droits de l'homme et relations internationales, v. 97, n. 2, In: Recueil des cours, p. 293-429. Haia: Nijhoff, 1959.

HöFfE, Otfried. Immanuel Kant. München: Beck, 1996.

. O imperativo categórico do direito: uma interpretação da "Introdução à Doutrina do direito." In: Studia Kantiana, v. 1, n. 1, p. 203-236, 1998.

KANT, Immanuel. Kantswerke. Preussische Akademie der Wissenschaften; Kritik der reinen vernunft, v. 3, 1781; Zum ewigen frieden, v. 8, 1795; Anthropologie in pragmatischer hinsicht, v. 7, 1798; Metaphysische anfangsgründe der naturwissenschaft, v. 4, 1786; Über den gemeinspruch: das mag in der theorie richtig sein, taugt aber nicht für die praxis, v. 8, 1793; Rechtslehre, v. 6, 1797. Berlim: Walter de Gruyter. 
KaUlBACH, Friedrich. Immanuel Kant, 2. ed. Berlim/Nova York: Walter de Gruyter, 1982.

LEBRUN, Gérard. Uma escatologia para a moral. In: TERRA, Ricardo Ribeiro (ed.) Idéia de uma história universal de um ponto de vista cosmopolita, p. 75-101. São Paulo: Brasiliense, 1986.

LISSER, Kurt. Der begriff des rechts bei Kant. (1 ed. 1922). Vaduz/Liechtenstein: Topos, 1978.

MASSON, Joëlle; MASSON, Olivier. Notes. In: KAnT, Emmanuel. Doctrine. Oeuvres philosophiques, v. 3, p. 1415-1456, Bibliothèque de la Pléiade. Paris: Gallimard, 1986.

RenaulT, Alain. Présentation. In: KANT, Immanuel. Métaphysique des mours, p. 746. Paris: Flammarion, 1994.

SolARI, Giole. La filosofia politica, v. 2 - Da Kant a Comte. Roma: Laterza, 1974.

Terra, Ricardo Ribeiro. A política tensa. São Paulo: Iluminuras, 1995.

VILLEY, Michel. La 'Rechtslehre' de Kant dans l'histoire de la science juridique. (Tradução [francês]: M. Philonenko. Paris: Vrin, 1971). In: Critique de la pensée juridique moderne, p. 139-159. Paris: Dalloz, 1976. 
